\title{
Upper and Lower Body Segment Ratios from Birth to 18 years in Children from Western Maharashtra: Correspondence
}

Received: 16 July 2019 / Accepted: 9 September 2019/Published online: 16 October 2019

(C) Dr. K C Chaudhuri Foundation 2019

To the Editor: I read with great interest the article entitled 'Upper and lower body segment ratios from birth to 18 years in children from western Maharashtra' published in IJP by Kondpalle et al. [1]. Measurement of body proportion provides a useful clinical clue in the evaluation of children and adolescents with disorders of growth and puberty. Large normative data for upper to lower body segment ratio in Indian children are lacking and I thank the authors for this great work which will help in better evaluation of Indian children with growth abnormalities. The differences in US/LS ratio observed in the present study when compared with conventional figures make the study more interesting. Using the conventional figures (1.7 at birth to 1.3 at $3 \mathrm{y}$ of age), a large proportion of the Indian (western) normal infants and young children may be diagnosed to have short trunk whereas more than half of the normal adolescent girls ( $\geq 11 \mathrm{y}$ ) and boys ( $\geq 12 \mathrm{y}$ ) may be labeled eunuchoid using the conventional cut off of 0.9 [2]. The study clearly demonstrates the need for similar studies from other regions of India.

Utility of few previous studies was limited due to lack of standard deviation data to infer 'what is abnormal'. Though authors note this point, the standard deviation data is not provided for the present study. Providing standard deviation and/ or $95 \%$ confidence intervals would help to improve the evaluation of Indian (western) children and adolescents with growth disorders.

Vijaya Sarathi

Department of Endocrinology, Narayana Medical College, Nellore, Andhra Pradesh, India. E-mail: drvijayasarathi@gmail.com

\section{References}

1. Kondpalle S, Lote-Oke R, Patel P, Khadilkar V, Khadilkar AV. Upper and lower body segment ratios from birth to 18 years in children from western Maharashtra. Indian J Pediatr. 2019;86:503-7.

2. Kliegman RM, Jenson HB, Behrman RE, Stanton BF. Nelson Textbook of Pediatrics, 18th ed. Philadelphia: Saunders; 2007.

\section{Authors' Reply}

To the Editor: We thank the authors for their interest in our work. Body proportions are indeed very useful for the assessment of disproportionate short stature. We agree that while the current study on upper and lower segment ratios was conducted in Maharashtra, we have recently published a larger multicentric study on sitting height and leg length percentiles for Indian children [1, 2]. Three to 17-y-old healthy children from six states of India have been measured in the study [2].

We agree that standard deviations are required to infer what is normal or abnormal. However, the data that we have presented were smoothed using the LMS method, which adjusts for skewness [3]. Each reference curve was summarized by three smooth curves representing the median $(\mathrm{M})$, the coefficient of variation (S) and the skewness (L) of the measurement distribution. The data have thus been transformed and the curves are constrained to change smoothly with age; giving the SD values for the transformed variables would be inappropriate. We have however computed LMS values from which centiles can be calculated for making comparisons. LMS values for upper and lower segment for boys and girls are available on request.

Anuradha V. Khadilkar and Vaman Khadilkar Growth and Pediatric Endocrine Unit, Hirabai Cowasji Jehangir Medical Research Institute, Jehangir Hospital, Pune, Maharashtra, India. E-mail: anuradhavkhadilkar@gmail.com

\section{References}

1. Kondpalle S, Lote-Oke R, Patel P, Khadilkar V, Khadilkar AV. Upper and lower body segment ratios from birth to 18 years in children from western Maharashtra. Indian J Pediatr 2019;86:503-7.

2. Khadilkar A, Ekbote V, Kajale N, et al. Sitting height percentiles in 3-17-year-old Indian children: a multicentre study. Ann Hum Biol. 2019:1-5. doi: 10.1080/03014460.2019.1637936.

3. Cole TJ, Green PJ. Smoothing reference centile curves: the LMS method and penalized likelihood. Stat Med. 1992;11:1305-19. 